Original Article

\title{
A STUDY OF SERUM URIC ACID IN DIABETES M ELLITUS AND PRE- DIABETES IN A SOUTH INDIAN TERTIARY CARE HOSPITAL
}

\author{
Sudhindra Rao M. ${ }^{1}$, Bino John Sahayo ${ }^{2}$ \\ ${ }^{1}$ Assistant Professor, Department of Medicine; K.S. Hegde Medical Academy, Mangalore, Karnataka. \\ ${ }^{2}$ Assistant Professor, Department of M edicine, Sree M ookambika Institute of M edical Sciences. \\ Kulasekharam. KK Dist. T.N. \\ Correspondence: \\ Sudhindra Rao M. \\ Assistant Professor, Dept of M edicine, K S Hegde M edical Academy, M angalore. \\ E-mail : sudhi78_dr@yahoo.com Mobile : 09480158124
}

\begin{abstract}
:
Background : Several epidemiologic studies have reported that high serum levels of uric acid are strongly associated with prevalent health conditions such as obesity, insulin resistance, metabolic syndrome, essential hypertension and renal disease. This study aimed to investigate the level of serum uric acid in Type 2 diabetes mellitus, pre-diabetics and non diabetics (controls) in south Indian population.
\end{abstract}

Methods : Uric acid level was measured by Uricase-PAP methodology in patients with Diabetes ( $n=71$ )/Pre diabetes ( $n=12$ )/ Control groups ( $n=34$ ). Using ANOVA test, uric acid levels in the above three groups were compared based on age, sex and other factors which can affect uric acid level.

Results: The mean serum uric acid level was lower in control group ( $3.84 \mathrm{mg} / \mathrm{dl}$ ), rose in pre-diabetics ( $4.88 \mathrm{mg} / \mathrm{dl}$ ) and again decreased in diabetics $(3.78 \mathrm{mg} / \mathrm{dl})$. P value comparing control and pre-diabetes was $0.009, \mathrm{p}$-value comparing pre-diabetes and diabetes was 0.003 and $p$-value comparing control and diabetes was 0.982 ( $p$ value $\varangle .05$ being significant).

Conclusion : The serum uric acid level being higher in pre-diabetes than controls and lower in diabetes mellitus than pre-diabetes may serve as a potential inexpensive biomarker of deterioration of glucose metabolism.

Keywords : Serum uric acid, Diabetes mellitus, Pre-diabetes

\section{Introduction :}

Diabetes mellitus is a group of disorders characterized by chronic hyperglycemia associated with disturbance of carbohydrate, fat and protein metabolism due absolute or relative deficiency of insulin secretion or its action. International Diabetic Federation data shows that world Diabetes \& Pre-diabetes prevalence in 2007 is $5.7 \%$ and $7.5 \%$ respectively. In India Diabetes mellitus prevalence ranges from 0.4 to $3.9 \%$ in rural areas and from 9.3 to $16.6 \%$ in urban areas. Diabetes causes long term dysfunction of various organs like heart, kidneys, eyes, nerves and blood vessels. ${ }^{1}$ Age adjusted mortality rates among diabetics is 1.5 to 2.5 times higher than general population. M uch of this excessive mortality is attributable to cardiovascular disease. ${ }^{1}$

Uric acid is formed by the breakdown of purins and by direct synthesis from 5-phosphoribosyl pyrophosphate and glutamine. Serum urate levels vary with age and sex.
Most children have serum urate concentrations of 180 to $240 \mu \mathrm{mol} / \mathrm{l}(3.0$ to $4.0 \mathrm{mg} / \mathrm{dl}$ ). Levels begin to rise in males during puberty but remain low in females until menopause. Mean serum urate values of adult men and premenopausal women are 415 and $360 \mu \mathrm{mol} / \mathrm{L}$ (6.8 and $6.0 \mathrm{mg} / \mathrm{dl}$ ), respectively. After menopause, values for women increase to approximate those of men. In adulthood, concentrations rise steadily over time and vary with height, body weight, blood pressure, renal function, and alcohol intake. ${ }^{2,3}$

Several epidemiologic studies have reported that high serum levels of uric acid are strongly associated with prevalent health conditions such as obesity, insulin resistance, metabolic syndrome, diabetes, essential hypertension, and renal disease. ${ }^{4}$ Population- based studies have shown that hyperuricemia is an independent risk factor for cardiovascular disease (CVD). This association has been found to be particularly robust among 
individuals at high risk for CVD, including those with obesity, hypertension, diabetes and renal disease. ${ }^{4}$ With the above background, this study was done to examine the serum level of uric acid in diabetics, pre-diabetics and controls.

\section{Materials and M ethods :}

Study population: Patients were selected from both out patient and in patient departments of a tertiary care hospital in random method. It was conducted at SM IMS hospital, Kanyakumari district during the period of JuneSeptember 2010. The following information were collected- age, sex, history about present illness, history about diabetes mellitus, hypertension, cardiovascular diseases, drug history, habits including alcohol intake, smoking and diet. Physical examination findings noted.

Patients were assigned into Diabetes/Pre diabetes/Control groups based on Fasting and Postprandial Plasma Glucose level according to WHO Criteria. Patients with known diabetes mellitus on treatment for the same were also included in Diabetes group. Serum creatinine and uric acid levelsmeasured.

\section{Inclusion Criteria :}

1. Patients with Diabetes Mellitus(ADA criteria for diabetes)

2. Pre-diabetes (Impaired Fasting Glucose/Impaired Postprandial Glucose)

3. Non diabetics.

4. All age groups $\&$ both sexes.

\section{Exclusion Criteria :}

1. Patients with serum creatinine $>1.0 \mathrm{mg} / \mathrm{dl}$

Uric acid level was measured by Uricase- PAP methodology. Normal reference range for uric acid was $3-5.7 \mathrm{mg} / \mathrm{dl}$. Uric acid level in the above three groups were compared based on age, sex and other factors which can affect uric acid level. Using ANOVA test the significance of difference between uric acid levels in three groups was found out.

\section{Results :}

The study included total 117 subjects. The number of subjects in individual group was as follows: Diabetes mellitus - 71, Pre-diabetes - 12, Control -34. Males -32 and Females-85. Age ranged from 33-80 years. All diabetics had Type2 Diabetes mellitus. (Table-1) Percentage of males was less in prediabetic group. Mean age was less in prediabetic group. Percentage patients with associated conditions or drug intake which can increase uric level highest in diabetics and least in prediabetics. Percentage patients with associated conditions or drug intake which can decrease uric acid level were also highest in diabetics and least in pre diabetics. (Table-2, Figure-1)

The mean serum uric acid level is lower in control group $(3.84 \mathrm{mg} / \mathrm{dl})$, rose in pre-diabetics $(4.88 \mathrm{mg} / \mathrm{dl})$ and again decreased in diabetics $(3.78 \mathrm{mg} / \mathrm{dl}$ ). (Table-3, Figure-2) The difference in mean uric level between Pre-diabetes and other two groups was statistically significant. The difference in mean uric acid level between control and Diabetes mellitus was not statistically significant. Similar trend of rise in uric acid in pre-diabetes and further reduction in diabetes was seen when the groups were sub divided based on age and sex. (Table4, Figure3, 4)

\section{Discussion :}

This hospital based cross sectional study shows that serum uric acid level increased form controls to pre-diabetic subjects. The serum uric acid level further decreased in diabetic subjects. This trend is seen even when groups are subdivided based on age and sex. The confounding factors like age and number patients with other diseases and drug intake which can affect uric level were comparable in three groups. In spite of percentage of males being less in pre-diabetics the uric acid level was higher. The rise in uric acid in pre-diabetes and further reduction in diabetes mellitus was statistically significant (P-values are 0.009 and 0.003 respectively). But typical rise in serum uric level with age is not observed in individual groups. The typical higher uric acid level in men when compared to women in each age group is not observed. These findings doubt the true representation of samples.

\section{Hyperuricemia in metabolic and vascular disease:}

M etabolic syndrome is characterized by abdominal obesity with visceral adiposity, impaired glucose tolerance due to 
Table-1: Age and sex distribution in three groups

\begin{tabular}{|c|c|c|c|c|c|c|}
\hline \multirow{2}{*}{$\begin{array}{c}\text { Age } \\
\text { group(yr) }\end{array}$} & Diabetes & Diabetes & Prediabetes & Prediabetes & Control & Control \\
\cline { 2 - 7 } & Male & Female & Male & Female & Male & Female \\
\hline $31-40$ & 3 & 4 & 0 & 0 & 0 & 3 \\
\hline $41-50$ & 2 & 12 & 0 & 2 & 2 & 11 \\
\hline $51-60$ & 9 & 20 & 0 & 6 & 3 & 5 \\
\hline $61-70$ & 5 & 11 & 2 & 0 & 3 & 5 \\
\hline $71-80$ & 2 & 3 & 0 & 2 & 1 & 1 \\
\hline Total & $\mathbf{2 1}$ & 50 & $\mathbf{2}$ & 10 & $\mathbf{9}$ & $\mathbf{2 5}$ \\
\hline
\end{tabular}

Table-2: Baseline Characteristics of study groups

\begin{tabular}{|l|c|c|c|}
\hline & Diabetes & Pre-diabetes & Control \\
\hline$\%$ of males & 29.58 & 16.67 & 26.47 \\
\hline Mean age (years) & 55.89 & 59.75 & 54.82 \\
\hline $\begin{array}{l}\% \text { of patients with } \\
\text { factors } \uparrow \text { uric acid }\end{array}$ & 29.58 & 25 & 26.47 \\
\hline $\begin{array}{l}\% \text { of patients with } \\
\text { factors } \downarrow \text { uric acid }\end{array}$ & 11.27 & 8.33 & 8.82 \\
\hline
\end{tabular}

Table-3: Mean Serum Uric acid level in study groups

\begin{tabular}{|c|c|c|c|}
\hline & Control & Pre-diabetes & Diabetes \\
\hline $\begin{array}{l}\text { Mean Serum } \\
\text { Uric acid (mg/dl) }\end{array}$ & $3.84+/-0.88$ & $4.88+/-0.79$ & $3.78+/-1.03$ \\
\hline $\begin{array}{l}\text { P-value } \\
\text { P-value c } \\
\text { P-value }\end{array}$ & $\begin{array}{l}\text { mparing Con } \\
\text { mparing Pre- } \\
\text { mparing Con }\end{array}$ & $\begin{array}{l}\text { ol and Pre-dia } \\
\text { abetes and Di } \\
\text { ol and Diabet }\end{array}$ & $\begin{array}{l}\text { etes }=0.009 \\
\text { betes }=0.003 \\
=0.982\end{array}$ \\
\hline
\end{tabular}

Table-4: Mean serum uric acid level in study groups with respect to age and sex $(\mathrm{mg} / \mathrm{dl})$

\begin{tabular}{|c|c|c|c|c|c|c|}
\hline \multirow{2}{*}{$\begin{array}{c}\text { Age } \\
\text { group }\end{array}$} & Female & Female & Female & Male & Male & Male \\
\cline { 2 - 7 } & Control & Prediabetes & Diabetes & Control & Prediabetes & Diabetes \\
\hline $\mathbf{3 1 - 4 0}$ & 3.83 & $* *$ & 3.65 & $* *$ & $* *$ & 4.07 \\
\hline $\mathbf{4 1 - 5 0}$ & 3.84 & 4.8 & 4.18 & 5.4 & $* *$ & 2.85 \\
\hline $\mathbf{5 1 - 6 0}$ & 4.12 & 4.88 & 3.90 & 3.5 & $* *$ & 3.88 \\
\hline $\mathbf{6 1 - 7 0}$ & 3.18 & $* *$ & 3.75 & 3.97 & 5.15 & 3.32 \\
\hline $\mathbf{7 1 - 8 0}$ & 3.5 & 4.65 & 3.33 & 3.1 & $* *$ & 3.25 \\
\hline
\end{tabular}

Figure1: Baseline characteristics of study groups

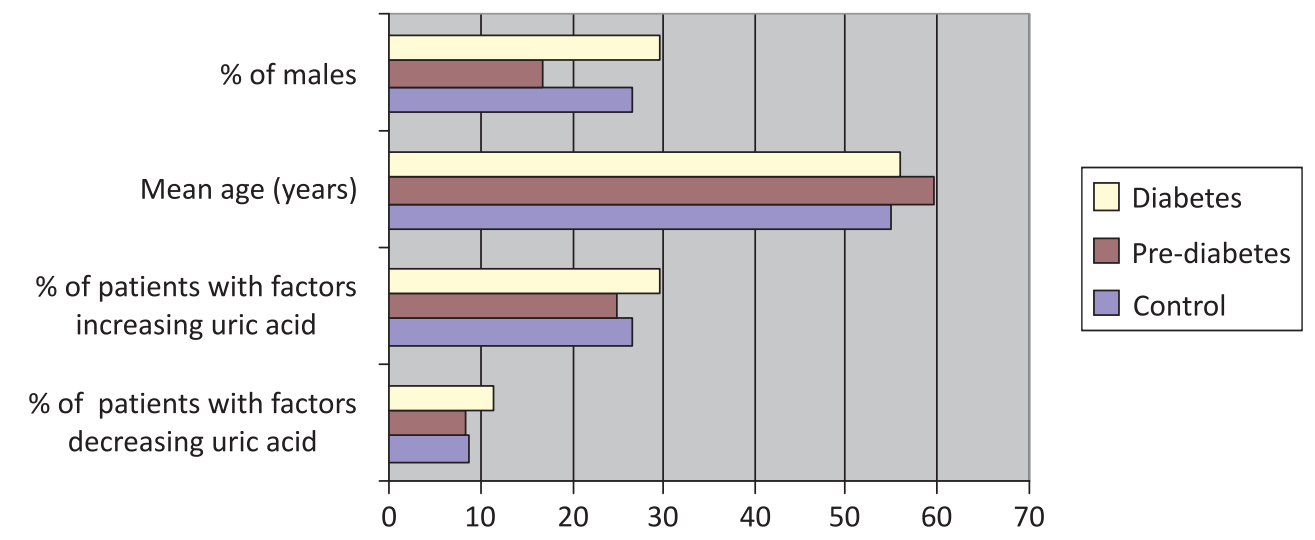

Figure2: Mean Serum Uric acid level $(\mathrm{mg} / \mathrm{dl})$ in study groups

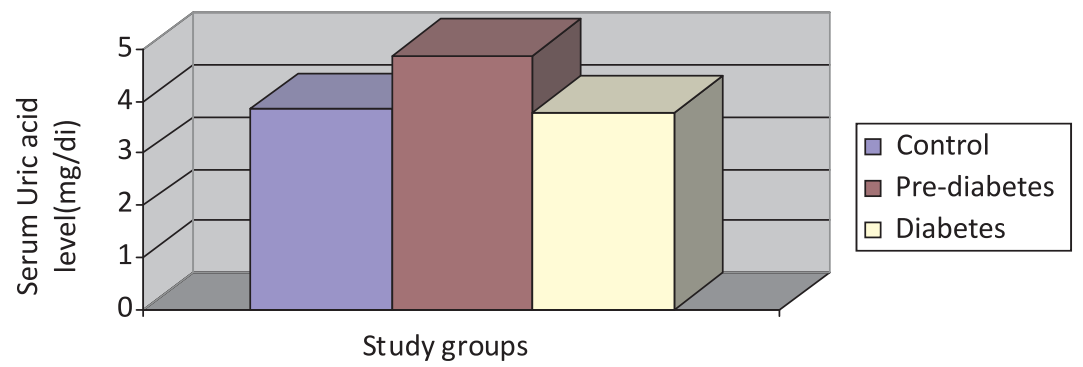


insulin resistance with hyperinsulinemia, hypertriglyceridemia, increased low-density lipoprotein cholesterol, decreased high-density lipoprotein cholesterol, and hyperuricemia. Hyperinsulinemia reduces the renal excretion of uric acid and sodium. Hyperuricemia resulting from euglycemic hyperinsulinemia may precede the onset of type 2 diabetes, hypertension, coronary artery disease, and gout in individuals with metabolic syndrome. ${ }^{2}$

Studies have shown that uric acid is significantly elevated in prediabetic stages and low in diabetes, and rises again after the development of renal insufficiency. ${ }^{5}$ Hyperuricemia has been found to be associated with obesity and insulin resistance, and consequently with type2 diabetes. Further potentially important biological effects of uric acid relate to endothelial dysfunction by inducing antiproliferative effects on endothelium and impairing nitric oxide production and inflammation, through increased Creactive protein expression, although these issues are considered controversial. Uric acid may play a role in immune activation with subsequent increased chemokine and cytokine expression. ${ }^{6}$

Various mechanisms have been suggested through which uric acid may be implicated in the atherosclerotic process and its clinical complications. Uric acid can act as a prooxidant, particularly at increased concentrations, and may thus be a marker of oxidative stress, but it may also have a therapeutic role as an antioxidant. It is unclear whether increased concentrations of uric acid in diseases associated with oxidative stress, such as atherosclerotic coronary heart disease, stroke, and peripheral arterial occlusive disease, are a protective response or a primary cause. ${ }^{6}$

In humans, uric acid is the most abundant aqueous antioxidant, accounting for up to $60 \%$ of serum free radical scavenging capacity and is an important intracellular free radical scavenger during metabolic stress. Serum uric acid concentrations are reduced in patients with type 1 diabetes and in regular smokers, which could increase susceptibility to oxidative damage and account for the excessive free radical production characteristically found in both groups. In type 1 diabetes, low serum uric acid concentrations occur because of abnormally high uric acid renal clearance. At the time of first clinical presentation, children and young adults already have detectably low serum antioxidant defenses and increased plasma oxidizability. ${ }^{7}$ Epidemiologic studies suggest that serum uric acid levels are heritable. Genetic correlations between serum uric acid and other cardiovascular risk factors, such as body mass index, waist circumference, systolic BP, and pulse pressure, were identified, suggesting that the genes associated with uric acid level are also associated with these phenotypes. ${ }^{8}$ Measurement of uric acid is easy in terms of preanalytics, can be performed with simple methods in routine laboratories, and is inexpensive. Thus, a preventive, cost effective approach is available with potential implications for publichealth. ${ }^{6}$

H.K.Choi, et al in their study of Haemoglobin Alc, fasting glucose, serum C-peptide and insulin resistance in relation to serum uric acid levels, observed that serum uric acid levels and the frequency of hyperuricaemia increased with moderately increasing levels of $\mathrm{HbAlC}$ and FPG and then decreased with further increasing levels of HbAlc (a bellshaped relation). ${ }^{5}$ Hairong Nan, et al in their study Serum uric acid, plasma glucose and diabetes showed that serum UA concentration increased with increasing FPG levels up to the FPG level of $7.0 \mathrm{mmol} / \mathrm{l}$, but notably decreased when FPG over $7.0 \mathrm{mmol} / \mathrm{l}$. An increasing trend in the UA concentration at the $2 \mathrm{hPG}<10.0 \mathrm{mmol} / \mathrm{l}$ and a decreasing trend at $2 \mathrm{hPG} \geq 10.0 \mathrm{mmol} / \mathrm{I}$ was also observed. ${ }^{7}$ Chien et al., in a well-conducted, large, population- based study, investigated the association between increased plasma concentrations of uric acid and the incidence of type 2 diabetes in Chinese subjects followed for a median of 9 years, during which 548 new cases occurred. In crosssectional analysis, they found an association with the metabolic syndrome and uric acid, in their prospective approach, could demonstrate a $63 \%$ increased risk for incident type 2 diabetes across extreme quintiles of uric acid in multivariable analyses. ${ }^{9}$ Ohlson LO etal., showed that the baseline serum uric acid level has also been found to independently predict the $2 \mathrm{hPG}$ levels during 13.5 years follow-up in a Swedish male population. ${ }^{10}$ 
Figure3: Mean Serum Uric acid level $(\mathrm{mg} / \mathrm{dl})$ in female study groups with respect to age

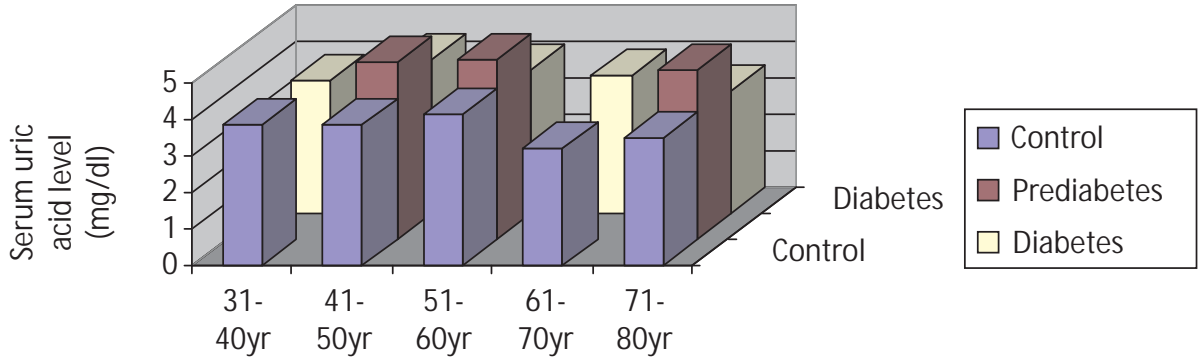

Figure4: Mean Serum Uric acid level (mg/ dl) in male study groups with respect to age

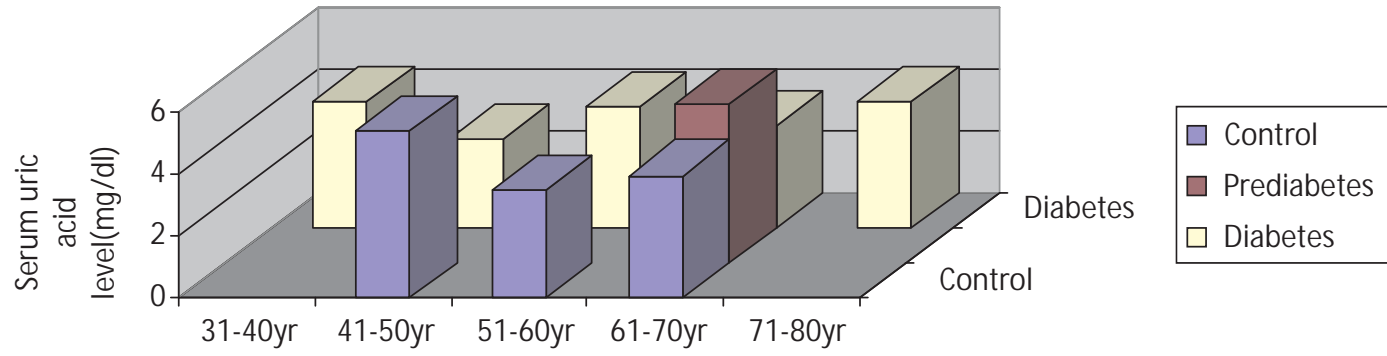

A biological mechanism underlying the bell-shaped relation between blood glucose levels and serum uric acid levels is thought to be due to the uricosuric effect of glycosuria, which occurs when the blood glucose level is greater than $180 \mathrm{mg} / \mathrm{dl}{ }^{11}$ Higher insulin levels are known to reduce renal excretion of urate. Insulin may enhance renal urate reabsorption via stimulation of the urate-anion exchanger URAT1 and/or the sodium-dependent anion cotransporter in brush border membranes of the renal proximal tubule. $^{12}$

Strength of present study- simple cost effective biochemical test like uric acid is used, which can guide the deterioration in glucose metabolism instead of using complex tests for measurement of insulin resistance. Uric acid level can also guide as a marker of cardiovascular disease which is the commonest cause of mortality in diabetes mellitus. The limitations of the present study include being a hospital based study; a community based study would yield better information. The number of participants is small for subgroup analysis. The Uric acid level is subjected to vary based on other co morbidities.

\section{Conclusion:}

The serum uric acid level was higher in pre-diabetes than controls and lower in diabetes mellitus than pre-diabetes. The uric acid may serve as a potential biomarker of deterioration of glucose metabolism. Pre-diabetics may be at higher risk of developing uric acid related complications like gout and nephropathy. A large community based prospective study in Indian population is needed to verify the findings.

\section{Acknowledgment :}

We are thankful to Sree M ookambika Institute of M edical Sciences and Hospital. Authors have declared that there is no conflict of interest. 


\section{References:}

1. K Park et al. Diabetes mellitus, in park's text book of preventive and social medicine, $20^{\text {th }}$ ed. Jabalpur, M/s Banarasidas Bhanos publication, 2009, pp 341-345.

2. Robert I. Wortmann et al. Disorders of purine and pyramidine metabolism, in Harrison's principle of internal medicine, 18th ed. Longo Dan Let al(eds). New York, M c Graw Hill, 2012, pp 3181-3185.

3. Victor w Rodwell et al.M etabolism nucleotides, in Harper's illustrated biochemistry, 28th ed. Robert murray et al (eds.). New York, M c Graw Hill, Lange publishers, 2009, pp287-289.

4. W. Stephen Waring, et al. , Uric Acid Restores Endothelial Function in Patients with Type 1 Diabetes and Regular Smokers. Diabetes 2006; 55: 3127-3132.

5. H. K. Choi and E. S. Ford. Haemoglobin Alc, fasting glucose, serum Cpeptide and insulin resistance in relation to serum uric acid levels-the Third National Health and Nutrition Examination Survey. Rheumatology 2008; 47: 713-717.

6. Editorial. Uric Acid, Type 2 Diabetes, and Cardiovascular Diseases:
Fueling the Common Soil Hypothesis? Clinical Chemistry 2008; 54:2:231-233.

7. Hairong Nan et al., Serum uric acid, plasma glucose and diabetes. Diabetes \& Vascular disease Research 2010; 7:40-46.

8. Subrata D. Nath, et al. , Genome Scan for Determinants of Serum Uric Acid Variability J Am Soc Nephrol 2007;18: 3156-3163.

9. Chien K-L, Chen M-F, Hsu H-C, Chang W-T, Su T-C, Lee Y-T, Hu FB. Plasma uric acid and risk of type 2 diabetes in a Chinese community. Clin Chem 2008; 54: 310-6.

10. Ohlson LO, Larsson B, Bjorntorp P, et al. Risk factors for type 2 diabetes mellitus. Thirteen and one-half years of follow-up of the participants in a study of Swedish men born in 1913. Diabetologia 1988; 31:798-805.

11. Cook DG, Shaper AG, Thelle DS, Whitehead TP. Serum uric acid, serum glucose and diabetes: relationships in a population study. Postgrad MedJ 1986; 62:1001-6.

12. Choi HK, M ount DB, Reginato AM . Pathogenesis of gout. Ann Intern M ed 2005; 143:499-516. 